\title{
Analisa Usaha Peternakan Ayam Broiler Pola Kemitraan Di Kecamatan Sumberejo Kabupaten Bojonegoro
}

\section{Livestock Business Analysis Broiler Chickens Partnership Pattern in District Sumberejo District Bojonegoro}

\author{
Wawan Indra Setyawan ${ }^{1}$, Ir. Mufid Dahlan, M.MA ${ }^{2}$, Drh. Dyah Wahyuning A, S.Pt ${ }^{3}$ \\ ${ }^{1}$ Mahasiswa Fakultas Peternakan \\ ${ }^{2}$ Dosen Pembimbing Utama \\ ${ }^{3}$ Dosen Pembimbing Pendamping \\ Program Studi Peternakan \\ Fakultas Peternakan, Universitas Islam Lamongan (UNISLA)
}

\section{RINGKASAN}

Pengumpulan data penelitian dilaksanakan pada tanggal 25 Mei - 25 Juni tahun 2016 di peternak peternak sekecamatan sumberrejo kabupaten bojonegoro. Tujuan penelitian ini adalah Mengetahui Analisa usaha Peternakan Ayam Broiler Pola Kemitraan di Kecamatan Sumberrejo Kabupaten Bojonegoro. Metode penelitian yang digunakan adalah jenis metode survei. Data yang digunakan dalam penelitian adalah data primer dan sekunder. Sampel digunakan sekaligus, merupakan keseluruhan dari jumlah peternak, hal tersebut dikarenakan peternak ayam broiler pola kemitraan di Kecamatan Sumberrejo Kabupaten Bojonegoro hanya berjumlah 14 peternak. Data yang diperoleh dianalisis secara deskriptif yaitu menggunakan tabel dari angka-angka yang tersedia, kemudian melakukan uraian dengan menggunakan rumus-rumus ekonomi sesuai dengan tujuan penelitian. Berdasarkan hasil penelitian Analisa Usaha Peternakan Ayam Broiler Pola Kemitraan Di Kecamatan Sumberrejo Kabupaten Bojonegoro mengalami pendapatan kenaikan tak menentu meskipun mengalami keuntungan. Rata rata keuntungan peternak tiap periode per ekornya adalah Rp. 15.237.790, Rp.17.100.188, dan Rp. 23.268.917. Analisis R/C bahwa usaha pemeliharaan ayam broiler mengalami keuntungan karna nilai R/C $>1$, nilai rata rata $\mathrm{R} / \mathrm{C}$ satu kecamatan yaitu 1,045. Dan berdasarkananalisis BEP produkdan BEP harga dalam 3 periode terakhir masih naik turun baik itu BEP produk maupun BEP harga. Namun demikian usaha peternakan ayam broilersatu kecamatan Sumber rejo tetap mengalami titik impas, tidak mengalami keuntungan dan tidak mengalami kerugian, jika nominal angka rata rata BEP produk hanya 16.380 ekor dan BEP harga hanya Rp. 16.170. Kesimpulan yang dapat diambil adalah meninjau dari analisis yang diteliti oleh penulis maka usaha masih layak untuk dijalankan dan dikembangkan. Saran yang bisa diberikan pada penelitian ini pada peternakan ayam broiler agar mencari alternatif lain guna menekan biaya operasional selama proses produksi supaya untung lebih besar lagi.

\section{ABSTRACT}

The data collection study conducted on 25 May - 25 June of the year 2016 for ranchersDistrictSumberrejoCityBojonegoro. The purpose of this research is the Analysis effort Poultry Broiler Sumberrejo Partnership in the city of Bojonegoro. The method used is the type of survey methods. The data used in this study are primary and secondary data. samples were used at the same time, the whole of the number of farmers, it is because broiler breeders partnership scheme in the District SumberrejoBojonegoro only amounted to 14 farmers. Data were analyzed using descriptive table of the figures available, then do a description using the formula economic formula in accordance with the purpose of research. Based on the results of research analyzes broiler chicken farm partnership model in the sub district Sumberrejobojonegoro experiencing erratic rise in revenue despite having the advantage. Average gainperiod tail breeder is Rp. 15.23779, Rp.17.100.188, and Rp. 23,268,917. Analysis of R/C that the maintenance effort broiler experiencing gains because the value of $R / C>1$, the value of the average $\mathrm{R} / \mathrm{C}$ one district is 1,045. And based on the analysis BEP products and BEP prices in the third period of the last still up and down both BEP products and BEP prices. However, the broiler chicken farm Sumberrejo districts continue to experience breakeven, did not experience gains and losses, if the average 
nominal rate only 16,380 tails product BEP and BEP for only Rp. 16,170. The conclusions of the analysis is to review examined by the authors, the effort is still DESERVE to be run and developed. The advice can be given in this study on broiler chicken farms in order to look for other alternatives in order to reduce operating costs during the production process in order to gain even greater.

Keyword: Business Analysis, Broiler Chicken, Partnership.

\section{PENDAHULUAN}

Peternakan merupakan salah satu dari lima subsektor pertanian. Peternakan adalah kegiatan memelihara hewan ternak untuk dibudidayakan dan mendapatkan keuntungan dari kegiatan tersebut (Rasyaf, 2002). Subsektor peternakan terbagi menjadi ternak besar, yaitu sapi (Perah/potong), kerbau, dan kuda, dan ternak kecil yang terdiri dari kambing, domba, dan babi serta ternak unggas (ayam, itik, dan burung puyuh).

Kegiatan usaha yang menarik dikaji di subsektor peternakan adalah usaha agribisnis ayam ras pedaging. Ayam pedaging disebut juga ayam broiler merupakan salah satu komoditi peternakan yang cukup menjanjikan karena produksinya yang cukup cepat untuk kebutuhan pasar dibandingkan dengan produk ternak lainnya, selain itu keunggulan ayam broiler antara lain pertumbuhanya yang sangat cepat dengan bobot badan yang tinggi dalam waktu yang relatif pendek, konversi pakan kecil, siap dipotong pada usia muda serta menghasilkan kualitas daging berserat lunak. Perkembangan yang pesat dari ayam broiler ini juga merupakan upaya penanganan untuk memgimbangi kebutuhan masyarakat terhadap daging ayam.

Ayam broiler merupakan jenis ras unggulan hasil persilangan dari bangsa-bangsa ayam yang memiliki daya produktivitas tinggi, terutama dalam memproduksi daging ayam. Sebenarnya ayam broiler ini baru populer di Indonesia sejak tahun 1980-an dimana pemegang kekuasaan mencanangkan penggalakan konsumsi daging ruminansia yang pada saat itu sulit keberdayaanya. Hingga kini ayam broiler telah dikenal masyarakat Indonesia dengan berbagai kelebihanya. Hanya 5-6 minggu sudah bisa dipanen, dengan waktu pemeliharaan yang relatif singk 1 dan menguntungkan, maka banyak peterr 1 baru serta peternak musiman yang bermunculan diberbagai wilayah Indonesia.

Perkembangan perunggasan selalu bergejolak setiap saat, hal ini bisa dilihat dari harga produk perunggasan yang selalu naik turun bahkan tidak hanya mingguan tetapi sampai harga harian. Naik turunya harga dipengaruhi oleh berbagai faktor antara lain daya beli masyarakat terhadap produk perunggasan itu sendiri. Oleh karena itu usaha perunggasan dikategorikan sebagai usaha beresiko tinggi (high risk). Pelaku usaha perunggasan terutama pada ayam broiler sebagian besar adalah perusahaan swasta, untuk itu perkembangannya tidak diperlukan lagi campur tangan pemerintah akan tetapi pemerintah berkewajiban membantu menjaga keseimbangan supply demand agar tidak terjadi gejolak supply maupun demand.

Beberapa permasalahan utama dalam industri perunggasan antara lain: (1) masalah penyediaan bahan baku pakan unggas dimana sebagian bahan baku pakan ternak penting harus diimpor, (2) adanya indikasi ketimpangan struktur pasar baik pada pasar input maupun output, (3) industri perunggasan komersial sangat rentan terhadap gejolak eksternal seperti krisis moneter dan wabah penyakit ternak seperti flu burung.

Usaha ternak ayam pedaging di bagi menjadi dua pola, yaitu pola mandiri dan pola kemitraan. Peternak mandiri prinsipnya menyediakan seluruh input produksi dari modal sendiri dan bebas memasarkan produknya. Pengambilan keputusan mencakup kapan memulai beternak dan memanen ternaknya, serta seluruh keuntungan dan resiko ditanggung sepenuhnya oleh peternak (Supriyatna dkk, 2006). Ada beberapa faktor yang menyebabkan usaha peternakan ayam broiler tetap dikelola secara mandiri oleh sebagian besar peternak ayam ras pedaging yaitu: 1. Pemeliharaanya cukup mudah; 2). Waktu pemeliharaan relatif singkat $( \pm \quad 4$ minggu $)$ karena sistim pemasarannya dalam bentuk ekoran; dan 3). Tingkat pengembalian modal relatif cepat. Namun selain itu ada beberapa hal yang menjadi kendala yaitu: 1). Sarana produksi kurang; 2). Manajemen pemeliharaan/keterampilan peternak yang belum memadai; 3 ). Modal relatif terbatas; 
4). Resiko pemasaran/penjualan cukup besar. 5). Usaha tergantung situasi dan cenderung spekulatif, dimana besar kemungkinan untuk memperoleh keuntungan yang tinggi, tetapi besar pula kemungkinan untuk menderita kerugian.

Pola kemitraan adalah usaha peternakan ayam broiler yang dilaksanakan dengan pola inti plasma, yaitu kemitraan antara peternak mitra dengan perusahaan mitra, dimana kelompok mitra bertindak sebagai plasma, sedangkan perusahaan mitra sebagai inti. Pada pola inti plasma kemitraan ayam ras pedaging yang selama ini, perusahaan mitra menyediakan sarana produksi peternakan (sapronak) berupa: DOC, pakan, obat-obatan, vitamin, bimbingan teknis dan memasarkan hasil, sedangkan plasma menyediakan kandang dan tenaga kerja. Faktor pendorong peternak ikut pola kemitraan adalah: 1). Tersedianya sarana produksi peternakan; 2). Tersedia tenaga ahli; 3). Modal kerja dari inti; 4). Pemasaran terjamin. Namun ada beberapa hal yang menjadi kendala bagi peternak pola kemitraan yaitu: 1). Rendahnya posisi tawar pihak plasma pada pihak inti; 2). Terkadang masih kurang transparan dalam penentuan harga input maupun output (ditentukan secara sepihak oleh inti). Ketidakberdayaan plasma dalam mengontrol kualitas sapronak yang dibelinya menyebabkan kerugian bagi plasma.

Seiring dengan mulai membaiknya perekonomian nasional dan meningkatnya daya beli masyarakat yang mengakibatkan meningkatnya permintaan daging ayam broiler sehingga mengakibatkan naiknya harga daging ayam broiler. Kondisi ini meranggsang peternak mandiri untuk kembali mengusahakan ayam ras pedaging namun karena terbatasnya modal, peluang tersebut sulit diraih oleh peternak mandiri, kecuali bila merubah pola mandiri ke pola kemitraan. Dalam program kemitraan ayam ras pedaging, nampaknya pola kemitraan dianggap sebagai suatu konsep yang tepat dalam memecahkan masalah keberlangsungan usaha peternakan rakyat. Melalui kemitraan diharapkan dapat secara cepat dapat bersimbiosis mutualistik sehingga kekurangan dan keterbatasan peternak dapat teratasi. Beralihnya peternak ayam ras pedaging dari usaha pola mandiri ke pola kemitraan berarti mengubah struktur industri perunggasan broiler rakyat. Hal ini berdampak pada pendapatan peternak.

Kabupaten Bojonegoro, khususnya Kecamatan Sumberrejo merupakan salah satu wilayah yang mengembangkan peternakan ayam broiler. Di Kabupaten Bojonegoro populasi ternak ayam Broiler tertinggi di Kecamatan Sumberrejo, terendah di Kecamatan Margomulyo dan Ngasem. Di Kecamatan Sumberrejo populasi ternak ayam broiler tertinggi didesa Sambongrejo, Wotan, Karangdowo dan yang terendah didesa Mejuwet (Dinas Peternakan Kabupaten Bojonegoro).

Adapun survey awal lokasi yang telah dilakukan sebelumnya diketahui bahwa peternakan yang memelihara ayam broiler di Kecamatan Sumberrejo Kabupaten Bojonegoro berjumlah 14 peternak, semuanya bekerja sama dengan beberapa perusahaan kemitraan. Berdasarkan dari fakta tersebut sehingga menimbulkan ketertarikan penulis untuk melakukan penelitian dengan judul Analisa Usaha Peternakan Ayam Broiler Pola Kemitraan Di Kecamatan Sumberrejo Kabupaten Bojonegoro.

\section{JENIS PENELITIAN}

Jenis penelitian yang digunakan adalah metode survei. Seperti yang disampaikan oleh Arikunto, (2006) bahwa, survei adalah pengamatan langsung ke lapangan untuk mengetahui obyek yang akan diteliti. Data yang digunakan dalam penelitian adalah data primer dan sekunder.

\section{METODE PENGUMPULAN DATA}

Metode pengumpulan data yang dilakukan pada penelitian ini antara lain:

a. Observasi yaitu pengumpulan data yang dilakukan melalui pengamatan secara langsung terhadap kondisi lokasi penelitian, serta berbagai aktivitas peternak dalam melakukan usaha peternakan ayam broiler.

b. Wawancara yaitu pengumpulan data yang dilakukan melalui wawancara langsung dengan pihak peternak yang melakukan usaha peternakan ayam broiler. 


\subsubsection{Analisis Biaya \\ ANALISIS USAHA}

Total biaya produksi adalah semua pengeluaran untuk proses produksi selama pemeliharaan pada periode tertentu yang dirumuskan sebagai berikut (Suratiyah, 1996 dalam Hartono, 2008):

$$
\mathbf{T C}=\mathbf{F C}+\mathrm{VC}
$$

Keterangan:

$\mathrm{TC}=$ Total cost atau total biaya produksi (Rp/periode)

$\mathrm{FC}=$ Fixed cost atau biaya tetap usaha budidaya (Rp/periode)

$\mathrm{VC}=$ Variable cost atau biaya tidak tetap usaha budidaya ( $\mathrm{Rp} /$ periode).

\subsubsection{Analisis Penerimaan}

Menurut Candra (2012) Total penerimaan usaha merupakan semua penerimaan yang didapatkan dari penjualan yang belum dikurangi dengan biaya produksi yang dirumuskan sebagai berikut:

$$
\begin{aligned}
& \mathrm{TR}=\left(\mathrm{TR}_{1} \times \mathrm{P}\right)+\left(\mathrm{TR}_{2} \times \mathrm{P}\right)+\left(\mathrm{TR}_{3} \times \mathrm{P}\right) \\
& \text { Keterangan : }
\end{aligned}
$$

$\mathrm{TR}=$ Total revenue atau total penerimaan

$\mathrm{TR}_{1}=$ Tingkat produksi daging $(\mathrm{kg})$

$\mathrm{TR}_{2}=$ Kotoran $/$ Feses $(\mathrm{Rp})$

$\mathrm{TR}_{3}=$ Karung Bekas Pakan (Rp)

$\mathrm{P}=$ Harga jual per unit (Rp).

\subsubsection{Analisis Pendapatan}

Pendapatan adalah selisih antara total penerimaan dengan total biaya produksi yang telah dikeluarkan yang dirumuskan sebagai berikut (Suratiyah, 1996 dalam Hartono, 2008):

$$
\boldsymbol{\pi}=\mathbf{T R}-\mathbf{T C}
$$

Keterangan:

$\pi=$ Pendapatan usaha ( $\mathrm{Rp} /$ periode $)$

$\mathrm{TR}=$ Total revenue atau total penerimaan usaha (Rp/periode)

$\mathrm{TC}=$ Total cost atau total biaya produksi usaha (Rp/periode).

\subsubsection{Analisis $\mathrm{R} / \mathrm{C}$ ratio}

$\mathrm{R} / \mathrm{C}$ ratio merupakan perbandingan antara penerimaan total dan biaya total. Berikut rumus untuk menghitung $\mathrm{R} / \mathrm{C}$ ratio (Hartono, 2012):

$$
\mathrm{R} / \mathrm{C} \text { ratio }=\frac{\text { penerimaan }}{\text { total biaya produksi }}
$$

Keterangan :

$$
\begin{array}{ll}
\mathrm{R} & =\text { Revenue }(\mathrm{Rp} / \text { Periode }) \\
\mathrm{C} & =\text { Cost }(\mathrm{Rp} / \text { Periode })
\end{array}
$$

\subsubsection{Break Even Point (BEP)}

BEP merupakan suatu keadaan dimana sebuah perusahaan tidak mengalami kerugian atau memperoleh keuntungan yang dirumuskan sebagai berikut (Candra, 2012)

$$
\begin{aligned}
B E P_{\text {harga }} & =\frac{\text { Biaya total }(R p)}{\text { hasil produksi }(k g)} \\
B E P_{\text {produk }} & =\frac{\text { biaya total }(R p)}{\text { harga ayam broiler }(R p)}
\end{aligned}
$$

\section{HASIL DAN PEMBAHASAN}

Biaya produksi dapat di golongkan dalam biaya tetap dan biaya tidak tetap. Biaya tetap dan biaya tidak tetap merupakan biaya produksi yang dikeluarkan usaha peternakan untuk memproduksi agar mencapai target. Biaya yang dikeluarkan tiap periode masa panen beransur naik turun. Sedangkan yang memiliki nilai pengeluaran paling banyak adalah pada pakan, dikarenakan mengikuti stok pakan yang ada maka pakan tidak bisa konsisten pada satu pakan saja, yang mempengaruhi pada harga dan biaya yang akan dikeluarkan. Dari lampiran 4 . Di pola tabel, dapat diperoleh data biaya tetap dan tidak tetap per ekor per periode adalah sebagai berikut.

Tabel 4.5.1: Biaya Tetap Per-Periode Per-Ekor

\begin{tabular}{|l|l|c|c|}
\hline $\begin{array}{l}\text { N } \\
\text { o. }\end{array}$ & \multicolumn{1}{|c|}{ Biaya tetap } & $\begin{array}{c}\text { Jumlah } \\
\text { /ekor }\end{array}$ & \% \\
\hline 1. & $\begin{array}{l}\text { Biaya penyusutan } \\
\text { kandang }\end{array}$ & Rp. 454 & 66 \\
\hline 2. & $\begin{array}{l}\text { Penyusutan peralatan } \\
\text { kandang }\end{array}$ & Rp. 51 & 6 \\
\hline 3. & Sewa lahan & Rp.230 & 28 \\
\hline & \multicolumn{1}{|c|}{ Total } & Rp. 735 & 100 \\
\hline
\end{tabular}

Sumber : Data Primer Yang Telah Diolah, 2016 
Tabel. 4.5.2: Biaya Tidak Tetap Per-Periode PerEkor

\begin{tabular}{|c|c|c|c|}
\hline No. & $\begin{array}{c}\text { Jenis } \\
\text { penerimaan }\end{array}$ & $\begin{array}{l}\text { Jumlah } \\
\text { /ekor }\end{array}$ & $\%$ \\
\hline 1. & Daging & 30.594 & 98 \\
\hline 2. & Kotoran/Feses & 195 & 0,63 \\
\hline 3. & $\begin{array}{l}\text { Karung bekas } \\
\text { pakan }\end{array}$ & 121 & 0,39 \\
\hline & Total & 30.910 & 100 \\
\hline
\end{tabular}

\section{Tabel Biaya Tidak Tetap/Ekor/Periode}

\begin{tabular}{|c|c|c|c|}
\hline No. & Biaya & Jumlah & $\%$ \\
\hline 1. & $\begin{array}{l}\text { Vaksin, Vitamin, Dan } \\
\text { Obat - Obatan. }\end{array}$ & Rp. 307 & 1 \\
\hline 2. & Pemanas & Rp. 140 & 0,5 \\
\hline 3. & Skam dan Koran & Rp. 264 & 0,9 \\
\hline 4. & Listrik dan Air & Rp. 176 & 0,6 \\
\hline 5. & Pakan & Rp. 21.641 & 76 \\
\hline 6. & DOC & Rp. 5.719 & 20 \\
\hline \multirow[t]{2}{*}{7.} & Gaji Karyawan & Rp. 444 & 1 \\
\hline & Total & Rp. 28.691 & 100 \\
\hline
\end{tabular}

Sumber : Data Primer Yang Telah Diolah, 2016

Dari tabel diatas dapat disimpulkan bahwa dalam usaha peternakan ayam broiler, pakan memegang peranan yang sangat penting dalam menjamin kelangsungan hidup usaha tersebut. Dimana seperti yang di ketahui bahwa sebesar $76 \%$ dari total sarana produksi ternak di keluarkan untuk pembelian pakan, keberadaan pakan sangat mempengaruhi keberhasilan usaha peternak ayam broiler kususnya.

Tabel 4.5.3: Total Biaya Tetap Dan Tidak Tetap Per Periode Per Ekor.

\begin{tabular}{|l|l|c|c|}
\hline No. & $\begin{array}{c}\text { Jenis } \\
\text { Biaya }\end{array}$ & Jumlah/ekor & \% \\
\hline 1. & $\begin{array}{l}\text { Biaya } \\
\text { Tidak } \\
\text { Tetap }\end{array}$ & 28.691 & $97 \%$ \\
\hline 2. & $\begin{array}{l}\text { Biaya } \\
\text { Tetap }\end{array}$ & 735 & $3 \%$ \\
\hline & Total & 29.427 & $100 \%$ \\
\hline
\end{tabular}

Sumber : Data Primer Yang Telah Diolah, 2016

\subsection{Penerimaan}

Besar kecilnya penerimaan sangat bergantung pada jumlah dan kualitas pemeliharaan ayam broiler tersebut. Penerimaan usaha peternakan ayam broiler tidak hanya dari penjualan ayam, namun juga didapat dari penjualan kotoran dan penjualan karung bekas tempat pakan. Dari daftar tabel, dapat diperoleh data penerimaan per ekor per periode adalah sebagai berikut.

Per-Ekor

Tabel 4.6.1: Penerimaan Per-Periode

Sumber : Data Primer Yang Telah Diolah, 2016

\subsection{Pendapatan}

Siregar (1990) dalam Yoga (2008) mengatakan bahwa, pendapatan merupakan hasil selisih antara penerimaan dan biaya atau pengeluaran. Dari daftar tabel, dapat diperoleh data pendapatan per ekor per periode adalah sebagai berikut.

Tabel 4.7.1: Pendapatan Peternak PerPeriode Per-Ekor

\begin{tabular}{|l|l|c|}
\hline No. & \multicolumn{1}{|c|}{ Uraian } & Rp \\
\hline 1. & Total penerimaan /ekor & 30.910 \\
\hline 2. & Total biaya /ekor & 29.427 \\
\hline \multicolumn{2}{|l|}{ Total Pendapatan /ekor } & 1.483 \\
\hline
\end{tabular}

Sumber : Data Primer Yang Telah Diolah, 2016

\subsection{Break event point ( BEP )}

Menurut Munawir (2002) dalam Candra (2012) menyatakan, break even point dapat diartikan suatu keadaan di mana dalam operasi perusahaan, perusahaan tidak memperoleh laba dan tidak menderita rugi (penghasilan $=$ total biaya).

\subsection{R/C Ratio}

Berdasarkan analisis R/C bahwa usaha pemeliharaan ayam broiler mengalami keuntungan karena nilai $\mathrm{R} / \mathrm{C}>1$. Hal ini membuktikan bahwa usaha ayam broiler di Kecamatan Sumberrejo Kabupaten Bojonegoro layak untuk dijalankan dan dikembangkan. Berikut adalah tabel rata rata $\mathrm{R} / \mathrm{C}$ ratio dan BEP 3 periode terakhir.

\section{Kesimpulan}

- Nilai rata rata $\mathrm{R} / \mathrm{C}$ di kemitraan peternakan ayam broiler satu kecamatan 
Sumberrejo adalah 1,045 berarti peternakan ayam broiler Di Kecamatan Sumberrejo Kabupaten Bojonegoro layak di jalankan karena $\mathrm{R} / \mathrm{C}>1$.

- Berdasarkan analisis BEP produk dan BEP harga satu kecamatan Sumberrejo dalam 3 periode terakhir masih naik turun baik itu BEP produk maupun BEP harga. Namun demikian usaha peternakan ayam broiler se-kecamatan Sumberrejo tetap mengalami titik impas, tidak mengalami keuntungan dan tidak mengalami kerugian, jika nominal angka rata rata BEP produk hanya 16.380 ekor dan BEP harga hanya Rp. 16.170.

\section{Saran}

Dari penelitian ini dapat di sarankan kepada peternak agar mencari alternatif lain guna menekan biaya operasional selama proses produksi supaya untung lebih besar lagi.

\section{DAFTAR PUSTAKA}

Andrinof, D.2006. Analisis Pola Kemitraan Ayam Pedaging pada Peternak Plasma PT. Satwa Mirama Raya Di Kabupaten Malang.

Arikunto, Suharsimi. 2006. Prosedur Penelitian. Jakarta. PT. Rineka Cipta.

Arman. 2005. Faktor-Faktor Yang Mempengaruhi Produktivitas Kerja Peternak Sapi Perah Di Kecamatan Sinjai Barat Kabupaten Sinjai. Skripsi. Fakultas Peternakan. Universitas Hasanuddin . Makassar

Cahyono, B. 1995. Beternak Ayam Buras. CV Aneka. Yogyakarta

Candra, Simon DKK. 2012. Analisis Ekonomi Usaha Ayam Petelur Cv. Santoso Farm Di Desa Kerjen Kecamatan Srengat Kabupaten Blitar. Faculty of Animal Husbandry, University of Brawijaya Malang. 30/1/2015.

Daniel, M. 2002. Pengantar Ilmu Ekonomi Peternakan, Penerbit Bumi Aksara, jakarta.

Downey, W, D dan Erickson, S, P. 1992. Manajemen Agribisnis, Penerbit Erlangga. Jakarta.

Fadillah, Rony. 2006. Panduan Mengelola Peternakan Ayam Broiler. Jakarta. Agromedia Pustaka
Hardjosworo, P, S. dan Rukimiasih, M, S. 2000. Meningkatkan Produksi Daging. Penebar Swadaya. Yogyakarta.

Hartono, B. 2012.Ekonomi Bisnis Peternakan, UB Press. Malang.

Kartasudjana, R dan Edjeng. 2006. Manajemen Ternak Unggas. Yogyakarta.

Kuncoro, M. 2003, Metode Riset Untuk Bisnis Dan Ekonomi Bagaimana Meneliti Dan Menulis Tesis . Erlangga, Jakarta.

Linton, I. 1997. Kemitraan (Meraih Keuntungan Bersama). Halira, Jakarta.

Lestari, 1992. Pemeliharaan Ayam Broiler. CV. Yasaguna, Surabaya.

Mubyarto. 1986. Pengantar Ekonomi Pertanian. LP3ES, Jakarta.

Murtidjo, B.A. 1994. Usaha Peternakan Ayam Broiler. Penerbit Kanisius, Yogyakarta.

Rasyaf, M. 2004. Beternak Ayam Pedaging. Penebar Swadaya. Jakarta.

Rasyaf, M. 2002. Beternak Ayam Pedaging. Penerbit Kanisius. Yogyakarta.

Rasyaf, M. 2001. Pengolahan Produksi Ayam Pedaging. Kanisius, Yogyakarta.

Rasyaf, M. 1992. Pengolahan Usaha Peternakan Ayam Pedaging. Kanisius, Yogyakarta.

Salam, T dkk. 2006. Analisis Finansial Usaha Peternakan Ayam Broiler Pola Kemitraan, Jurnal Agrisistem, Juni 2006 Vol 2 No.1

Saragih, B. 2000. Agribisnis Berbasis Peternakan. Pustaka Wirausaha Muda, Bogor.

Sirajuddin, N. 2004. Analisis Produktivitas Kerja Peternak Pada Usaha Ayam Ras Pedaging Pola Kemitraan dan mandiri Di Kabupaten Maros. Tesis. Universitas Hasanuddin. Makassar.

Suharno, B. 2003. Kiat Sukses Berbisnis Ayam. Penerbit Penebar Swadaya, Jakarta.

Soekarwati. 2006. Analisis Usahatani. Penerbit Universitas Indonesia, Jakarta.

Soekarwati. 2002. Prinsip Dasar Manajemen Pemasaran Hasil-Hasil Pertanian Edisi Revisi. Raja Grafindo Persada, Jakarta.

Sumardjo, J. Sukalaksana Dan W. A. Darmono. 2004. Tori Dan Praktik Kemitraan Agribisnis. Penebar Swadaya, Jakarta. 
Supriyatna, Y dkk. 2006. Analisis Kelembagaan Kemitraan Usaha Ternak Ayam Ras Pedaging: Studi Kasus Di Propinsi Bali. Pusat Analisis

Sosial Ekonomi Dan Kebijakan Pertanian. Bogor.

Swastha dan Sukotjo. 1997. Pengantar Bisnis Modern. Penerbit Liberty. Yogyakarta.

Tohar, M. 2002. Membuka Usaha Kecil. Penerbit Kanisius, Yogyakarta.

Yoga, Marta Dwi. 2007. Skripsi. Analisis Pendapatan Usaha Peternakan Sapi Perah Rakyat Di Desa Wonokerto Kecamatan Bantur Kabupaten Malang. Program Studi Sosial Ekonomi Fakultas Peternakan Universitas Brawijaya Malang. 30/1/2015. 